\title{
SOA - THE LINK BETWEEN MODERN EDUCATIONAL TECHNOLOGIES AND MOBILE LEARNING IN THE HIGHER EDUCATION LANDSCAPE
}

\author{
Roxana Marina POPA STRAINU1, Mircea GEORGESCU²
}

DOI: 10.1515/tjeb-2017-0008

Modern educational technologies encompass a variety of variables such as people, processes, assets, environments, technology. These variables are part of a complex system which has some important properties and a final purpose: delivering learning material and keeping track of the recipient's evolution and development. The purpose of this paper is to define the system of modern educational technologies with the help of its variables and internal or external processes as well as to find where mobile learning fits in this large system. From a technical point of view we want to analyze whether Service Oriented Architecture $(\mathrm{SOA})$ is enough or proper to integrate mobile learning in this system. At the end we should be able to decide if dedicated mobile apps, or mobile friendly sites or a combination of those two are suited to deliver the results we are looking for with the support of SOA, if we consider the variety of devices and operating systems we are trying to integrate.

Keywords: $\quad \begin{aligned} & \text { Service Oriented Architecture (SOA), mobile learning, } \\ & \text { modern education, mobile learner }\end{aligned}$

JEL Classification: 121, 033, P46

${ }^{1}$ PhD Student, "Al. I. Cuza" University of Iasi, Romania.

2 Professor PhD, "Al. I. Cuza" University of Iasi, Romania. 
Popa Strainu, R. M., \& Georgescu, M. (2017).

SOA - the link between modern educational technologies and mobile learning

in the Higher Education Landscape

\section{Introduction}

The technology is the most rapidly growing area of interest in the last years. Hart stated that human invention can be conceived as new combinations of previously existing elements. If so, the opportunity for new inventions will increase roughly as a function of the number of possible permutations and combinations of available elements, which means that its increase will be a factorial of the number of elements. Starting from this statement, we can expect a rapidly growing number of technological inventions in any field.

Technology is everywhere and the latest developed devices are way faster and lighter than the ones developed 25 years ago. This means that the human inventions evolved at a high speed, driving new changes in the way people learn, communicate, shop and access information. Beside the advantage of time gained, technology brings the advantage of speed and of communication. Now, Internet is a must, mobile devices are ubiquitous, processors have higher speeds of processing, and information is available anytime and anywhere.

\section{Defining the system of modern education technologies}

Technology is defined as an aggregate of methods, systems and devices which are the result of scientific knowledge being used for practical purposes (Collins English dictionary). The Romanian dictionary (DEX) defines it as a science of methods used in materials processing, or the group of processes, methods, operations used with the purpose to create a certain product. Both definitions use two common terms: methods and processes as the workflow and the purpose (in Collins) seen as product (in DEX). From an educational point of view, the methods and processes represent the processing of existing resources (systems, devices) to provide knowledge and education, which represent the final products. But we argue that technology (meaning only devices) is not sufficient when we want to determine the educational technologies.

As Selwyn points out, when talking about technology in education, the authors only consider the devices: At this point, it is important to note that what is often referred to as "educational technology" is not a single entity, but a diverse array of technological devices and technologybased activities and practices. In fact, many discussions of educational technology are focused only on a small number of the various forms of digital technology that are used around the world. Instead, educational uses of digital technology encompass working with most internet-connected computing devices such as laptop, tablet computers, electronic smartboards, smart phones, etc., in the form of virtual learning environments (Selwyn, 2013, p. 6).

DE GRUYTER OPEN
Timisoara Journal of Economics and Business | ISSN: 2286-0991 | www.tjeb.ro Year 2017 | Volume 10 | Issue 1 | Pages: 120-133 
Popa Strainu, R. M., \& Georgescu, M. (2017).

SOA - the link between modern educational technologies and mobile learning

in the Higher Education Landscape

The above developments are blurring the boundaries between what has traditionally been seen as the "built learning environment" and the information and communications technologies that support those spaces. The rapidly emerging models of "technology enhanced learning environments" (TEAL) - first introduced at MIT in 2003 - emphasize that acoustics, furniture, lighting (both natural and artificial), mobility, flexibility, air temperature and security must support the educational technologies being designed for those spaces. The traditional physical elements are technologies as well, but these are increasingly interdependent with ICTs and audio-visual educational technologies. In our view, all of these elements should be integrated under the one heading of "learning technologies" and be considered within the same framework, whether it be budget, design, maintenance or flexibility (OECD, 2010, p. 2).

Technology alongside an education system creates an educational output. Actually the modern educational technologies encompass the intersection between Education, University/Institution and Technology as Figure 1 shows.

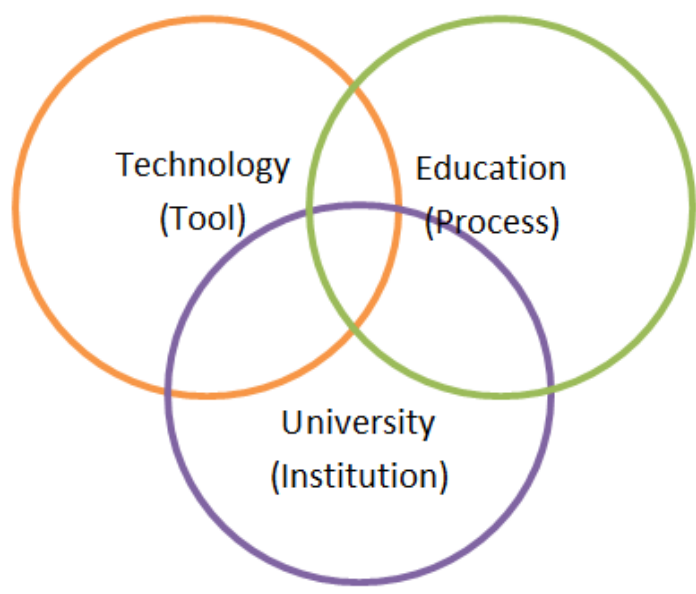

Figure 1. Where educational technologies emerge

Similar concepts, models and laws have often appeared in widely different fields, independently and based upon totally different facts. There are many instances where identical principles were discovered several times because the workers in one field were unaware that the theoretical structure required was already well developed in some other field (Bertalanffy, 1969, p. 34). This is why the systems theory will help us create the borders and a concept of this system, with the help of isomorphism or structural similarities mentioned by Bertalanffy in his book.

\section{DE GRUYTER} OPEN
Timisoara Journal of Economics and Business | ISSN: 2286-0991 | www.tjeb.ro Year 2017 | Volume 10 | Issue 1 | Pages: 120-133 
Popa Strainu, R. M., \& Georgescu, M. (2017).

A system can be defined as a complex of interacting elements (Bertalanffy, 1969, p. 55). According to David S. Walonick, a system represents a structure of components which can be analyzed as distinct entities (Walonick 1993, 84). This is why we say that the modern educational technologies represent a complex system, having its own components (subsystems) and processes. Technology (with its own components: hardware, software, communication, etc.) is a component, education is a component and a process at the same time, the university (institution) is a component.

From the general systems theory, we know that there are open and closed systems. By close systems, we can refer to the systems in physics or chemistry, where the system studied is completely closed (Bertalanffy, 1969, p. 32), while a system where an exchange of information exists between the system and the environment is an open system.

Now, using an analogy for an information system (IS), the author David Burgeois identifies six components of an IS:

- Hardware devices: the tangible part of an IS, physical components of the technologies (real system).

- Software: a set of instructions which says to the hardware part what to do. Software is split into operating systems and applications (abstract system).

- Data: a collection of facts, organized data (abstract system).

- Communication: the communication between devices using a physical network (mixed system).

- People: the essential component that uses the entire system (real system).

- The processes: a series of steps used to achieve a specific result (Burgeois 2014, 54).

Because modern education technologies involve mainly information systems as components, along with education as the main process, as well as the institution as the physical environment, we can add a new component to our system: the student. With this new element, the system of educational technologies becomes the one having the components from Figure 2. 
Popa Strainu, R. M., \& Georgescu, M. (2017).

SOA - the link between modern educational technologies and mobile learning in the Higher Education Landscape

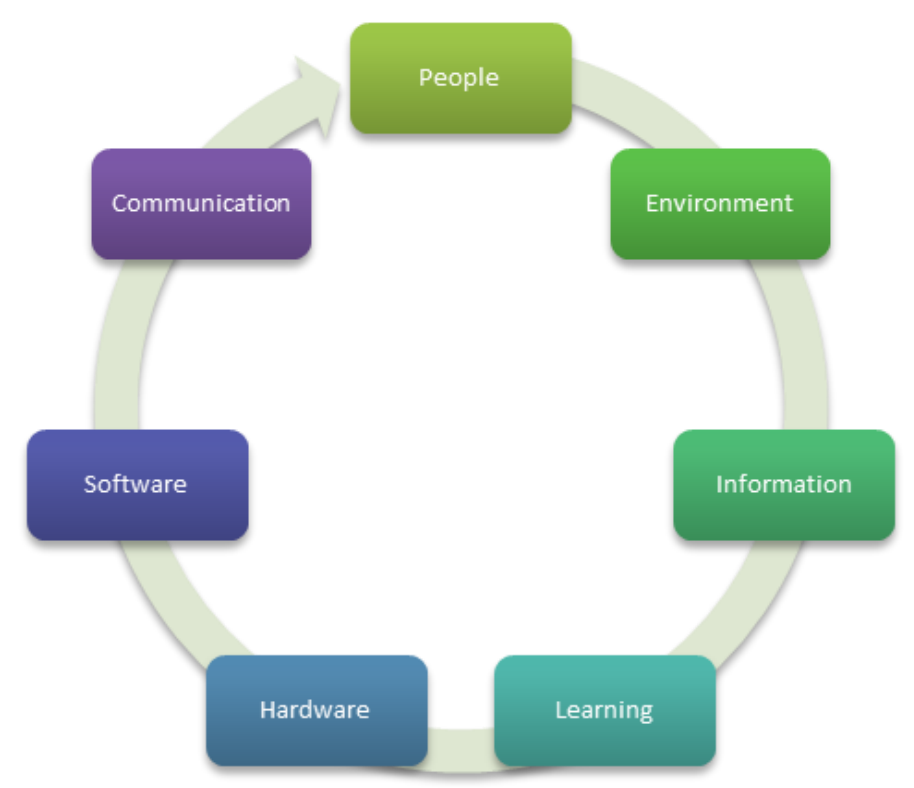

Figure 2. The components of the System of Educational Technologies

We can also say that this system is by its nature an open system, because there is a permanent exchange of information inside and outside the system.

\section{Aims and objectives of the research}

The software systems are now, thanks to the internet and www, interconnected, allowing people to communicate, to exchange information, data, audio, images and video. They are built and designed systems based on web applications principles: exchange of information via a network. Each website represents a web application being built using web technologies.

The main processes which occur in this system are learning and communication. They both are components (or elements) and processes (at the same time) which create motion and exchange of information between the components of the system, outside and inside the system, demonstrating the fact that this is an open system. Each component of a system can be real (tangible part of the system) or abstract (intangible part, such as symbols or concepts), so we can notice from these descriptions that this system has both types of elements.

DE GRUYTER OPEN
Timisoara Journal of Economics and Business | ISSN: 2286-0991 | www.tjeb.ro Year 2017 | Volume 10 | Issue 1 | Pages: 120-133 
Popa Strainu, R. M., \& Georgescu, M. (2017).

SOA - the link between modern educational technologies and mobile learning

in the Higher Education Landscape

In this context, the purpose of this paper is to define the system of modern education technologies, because starting from the system's theory concepts, we can state that education technology is a system. Secondly, mobile learning, an important part of education technologies, must be identified as a part of this system, but the question is: is mobile learning a system or a component? Lastly, is-service oriented architecture (SOA) enough to provide the exchange of information between mobile learning as part of the system of modern education technologies and its containing system?

\section{Research tasks and methodology}

To help our research we used Systems theory, to organize concepts, information, data, and processes, into large complex systems. First, a system can be decomposed in smaller individual components which can be analyzed as separate entities. At the same time, between these components, there is an interaction, such as processes or an exchange of information.

Considering the previously mentioned information, the research task resides in the research question formulated as follows: Could SOA be the link between modern educational technologies and mobile learning in the Higher Education Landscape? Is there an orientation of the educational process in Romania towards e/m-Learning educational technologies? In order to answer the above questions and to interpret them, we used an exploratory research methodology which combines direct observation with critical and synthetic analysis supplemented with bibliographical documentation. Thus, we attempted to seize the real situation of students' perception as active participants in the educational process in order to shape the trend that the student academic community in Romania needs to adopt under the circumstances of the current technological challenges.

\section{Major results: environments in educational technologies}

The system of educational technologies (SET) involves, not only IS, but also an environment where these components or subsystems work or exchange information. In this context, we have the physical environment (a building, a room, a park, etc.) where this system resides and exchanges information and a virtual environment where the software component of this system exchanges data. We can say that the physical space can be a containing system for SET and that the virtual environment is subsystem of SET.

In today's interconnected and technology-driven world, a learning environment can be virtual, online, remote; in other words, it doesn 't have to be a place at all. Perhaps a better way to think of the 21st century learning environments is as the support systems that organize the condition in which humans learn best - systems that accommodate the unique learning

\section{DE GRUYTER OPEN}

Timisoara Journal of Economics and Business | ISSN: 2286-0991 | www.tjeb.ro Year 2017 | Volume 10 | Issue 1 | Pages: 120-133 
Popa Strainu, R. M., \& Georgescu, M. (2017).

SOA - the link between modern educational technologies and mobile learning

in the Higher Education Landscape

needs of every learner and support the positive human relationships needed for effective learning. Learning environments are the structures, tools, and communities that inspire students and educators to attain the knowledge and skills the 21st century requires from us all. Technology, space, time, culture, and policy will be discussed separately since it is important to remember that their power is cumulative (Partnership Resource 21, 2009, p. 3)

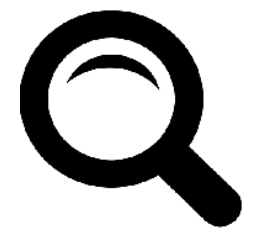

Gathering information

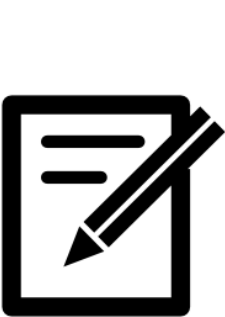

Publishing

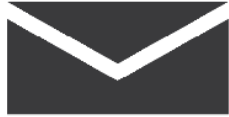

Communication

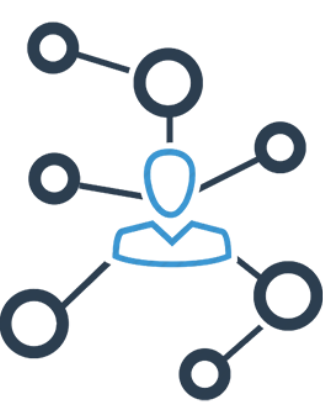

Networking

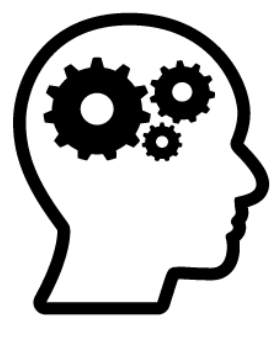

Lerning

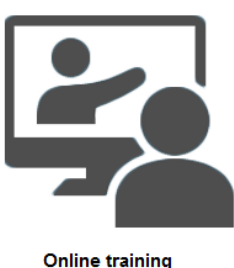

Online training

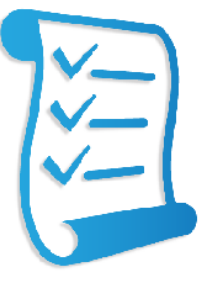

Evaluation
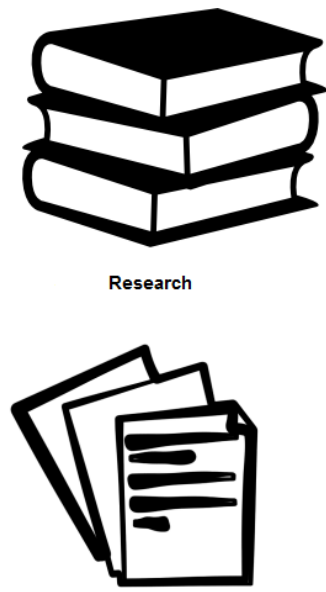

Training material

INFORMAL PLE

FORMAL PLE

Figure 3. The PLE informal (left) and formal (right)

The environment which contains this system of educational technologies, may be called Master Learning Environment (MLE) and can be the complex of buildings and spaces occupied by education institutions (schools, universities), the physical environment where learning takes place and which is contained by the system of educational technologies (physical spaces, rooms) will be called Learning Environments, while the virtual one can be referred to as Virtual Learning Environment (VLE). One notion which stands out in the literature review of VLE is the term of Personal Learning Environment (PLE). This is a virtual place where the learner can have his/her own privacy, the learning objectives are defined by the school, they have teacher support and it offers collaboration and communication facilities and access to information. Although it may be confused with the term of Learning Management System (LMS), these two are not necessarily the same in this conceptual context. And now, when we have the term of formal and informal in the field of learning, we can extend the meaning of these terms to create two categories of PLEs: formal and informal which can be seen in figure 3 .

DE GRUYTER OPEN
Timisoara Journal of Economics and Business | ISSN: 2286-0991 | www.tjeb.ro Year 2017 | Volume 10 | Issue 1 | Pages: 120-133 
Popa Strainu, R. M., \& Georgescu, M. (2017).

SOA - the link between modern educational technologies and mobile learning

in the Higher Education Landscape
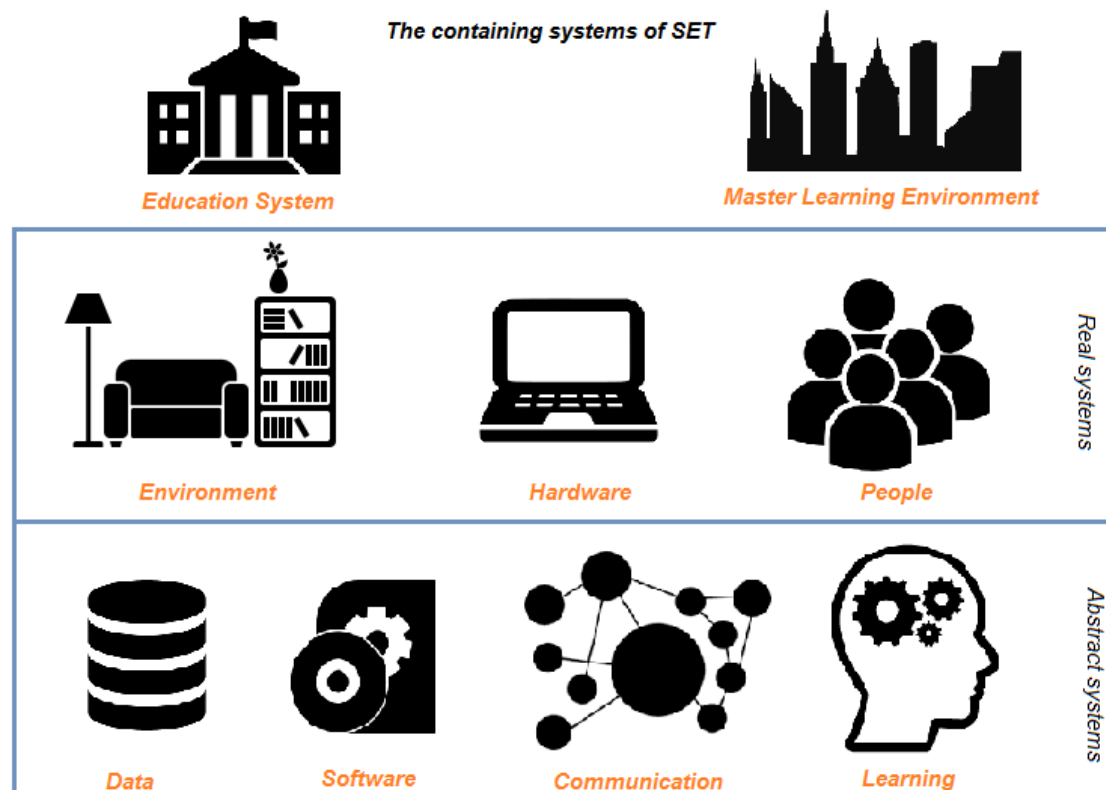

People

Software

Communication
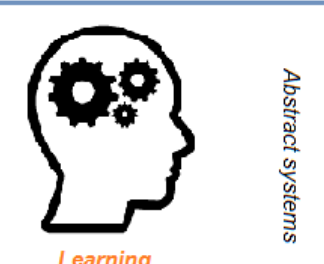

Figure 4. The System of Education (al) Technologies

We needed this short review and concept constructs in order to emphasize the fact that the software component of a SET may be as well considered a network of PLEs, linked via Internet. The MLE can also be a larger system for the SET, while LE is a component, because it provides the physical space where learning takes place, with the use of technology. After this short review of learning environments, we can have a final conceptual form for STE, which can be seen in the Figure 4.

\section{Mobile learning - a system or a component?}

We start from the beginning with the hypothesis that mobile learning is just a component of the SET, because mobile technology may be considered a subsystem of the whole technology. We want to demonstrate that mobile learning represents a complex system.

First, we need an accurate definition of mobile learning. Mobile learning - or m-learning- can be viewed as any form of learning that happens when mediated through a mobile device and a form of learning that established the legitimacy of 'nomadic' learners (El-Hussein, 2010, p. 5 ), or any type of learning that takes place in learning environments and spaces that take account of the mobility of technology, mobility of learners and mobility of learning (El-Hussein, 2010, p. 9). It also involves the use of mobile technology, either alone or in combination with OPEN 
Popa Strainu, R. M., \& Georgescu, M. (2017).

SOA - the link between modern educational technologies and mobile learning

in the Higher Education Landscape

other information and communication technology (ICT), to enable learning anytime and anywhere (Unesco, 2013, p. 6).

But the vast literature of mobile learning takes into account some key variables such as context, interaction, time, space, technology, content or control. By using these variables, we could establish our own definition of mobile learning as a learning process enabled by mobile devices, which can take place in any environment, facilitates the collaboration, content access and delivery, which can be controlled by both the student and the teacher and offers to the ones involved mobility in time and space. Starting from this definition we can extract some key components of this system of mobile learning technologies such as: devices (hardware), software, data, communication, people, the environment and the process of learning. In this case we can state that mobile learning may be considered a system just like the SET and we will use the short term of MLS to further address it in this paper.

Table 1. The differences between SET and MLS

\begin{tabular}{ccc}
\hline The component & SET & MLS \\
\hline Environment & Fixed, mobile & Mobile, can be anywhere \\
\hline Software & Windows, IOS, Linux, Android & Android, IOS, Windows Phone \\
\hline Hardware & Laptop, desktop, mobile devices & Only mobile devices \\
\hline
\end{tabular}

If we think to remove this MLS from SET, the last one will continue to function like before, so we can consider that although these systems share the same components or elements, they are not dependent. We consider that MLS is a separate system, with the same structure as SET, and between those two there is a permanent exchange of information due to the communication component. These systems may be seen as adjacent systems sharing the communication element, the data, people and the final objective and process represented by learning. In some cases, the environments are different because they are based on the advantage of user mobility and the software (the operating systems are especially designed for mobile technologies) and the hardware component are definitely different (table 1).

\section{Is SOA the link between MLS and SET?}

As we identified in the last section, MLS and SET share the communication element. This is the main component which triggers exchange of information between those two and ensures the openness of the systems. There is an entire science of communication technology which, in a very large sense, is based on the feedback scheme: a signal, a requester (receptor) and a receiver (effector) (see Figure 5). Because both systems are mostly based on the Internet which is provided by networks (broadband, wireless, 3G, 4G) and new technologies (web

DE GRUYTER OPEN
Timisoara Journal of Economics and Business | ISSN: 2286-0991 | www.tjeb.ro Year 2017 | Volume 10 | Issue 1 | Pages: 120-133 
Popa Strainu, R. M., \& Georgescu, M. (2017).

SOA - the link between modern educational technologies and mobile learning

in the Higher Education Landscape

technologies) emerged to support this type of communication and to send/receive data via Internet, the communication system is a vital part of these systems.

From this point we can see that the components (elements) involved in this analysis are the software and communication ones. While the hardware part ensures the infrastructure and the tools necessary to send data between devices (or sender/receiver pairs), the software component is the one that knows how to do this. This means that, in the context of a web application, the data is programmatically sent via Internet to another device (requester) based on a specific request. This is the principle of communication and the base for any web application which provides access to data.

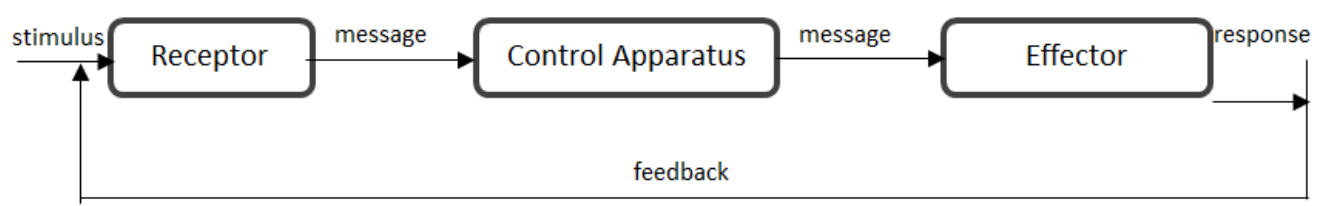

Figure 5. The feedback Scheme

In the software architecture, the things evolved from object oriented analysis and design to component based design and finally to service oriented architecture (SOA). Components can be seen as the mechanism to package, manage and expose services (Endrei, Ang, \& al, 2004, p. 20) and they are seen by Allen as an executable unit of code that provides physical blackbox encapsulation of related services. Its service can only be accessed through a consistent, published interface that includes an interaction standard. A component must be capable of being connected to other components (through a communications interface) to a larger group.

A service is generally implemented as a course-grained, discoverable software entity that exists as a single instance and interacts with applications and other services through a loosely coupled, message-based communication model (Endrei, Ang, \& al, 2004, p. 21). Services are designed without knowing who will be using them. In a service-oriented architecture, applications are built from services which communicate via messages using a process known as orchestration (Rosenberg, 2010, p. 3).

DE GRUYTER OPEN
Timisoara Journal of Economics and Business | ISSN: 2286-0991 | www.tjeb.ro Year 2017 | Volume 10 | Issue 1 | Pages: 120-133 
Popa Strainu, R. M., \& Georgescu, M. (2017).

SOA - the link between modern educational technologies and mobile learning

in the Higher Education Landscape
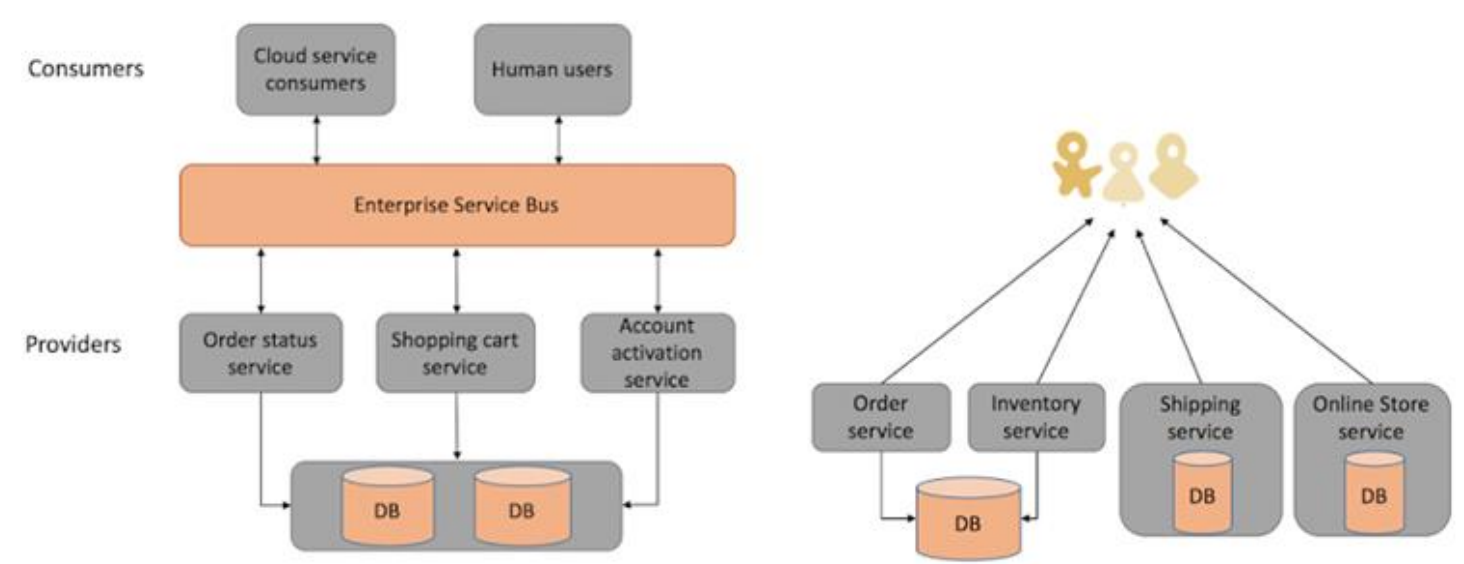

Figure 6. SOA Architecture vs Microservices Architecture

Source: Miri, 2016

SOA is an approach to build complex software systems from a set of reusable services that obey service-orientation principles, which can be built quickly, primarily from existing services. A service that obeys the principles of service-orientation is an autonomous, loosely coupled, and stateless unit of functionality that is made available by a formally defined interface (Rosenberg, 2010, p. 3, Endrei, Ang, \& al, 2004, p. 19). SOA is also based on the feedback mechanism, having a requester and a provider. The requester is also known as service consumer. The link between them is mediated by Enterprise Service Bus (ESB) which according to the concept is not a product, but an architectural best practice for implementing a service-oriented architecture (Endrei, Ang, \& al, 2004, p. 39) and it behaves as shown in Figure 7.

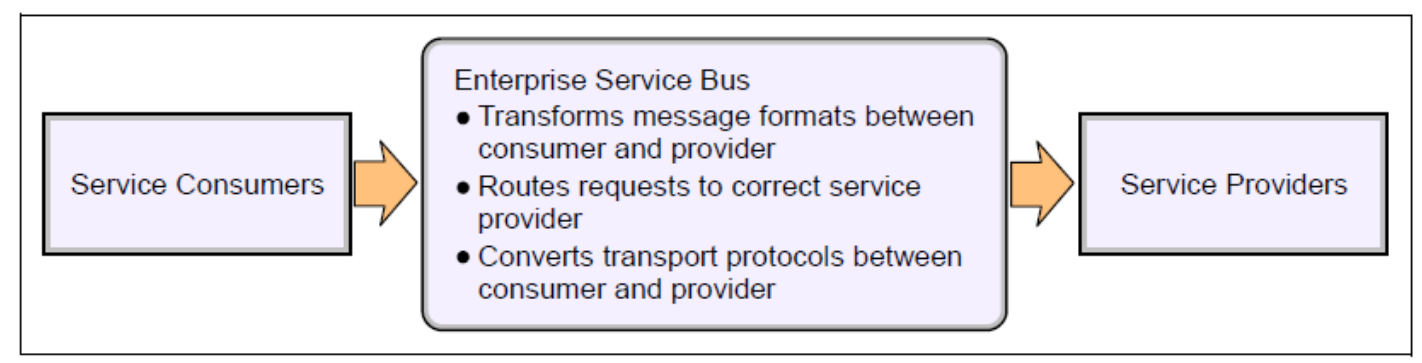

Figure 7. SOA Architecture vs Microservices Architecture

Source: Endrei, Ang et al. 2004, 39

With the description of a PLE from the section above (Environments in educational technologies), we can see that from the entire software system to the specific PLE, software components exist. If we analyze the functionalities of a PLE, we can even identify some basic

\section{DE GRUYTER} OPEN 
Popa Strainu, R. M., \& Georgescu, M. (2017).

SOA - the link between modern educational technologies and mobile learning

in the Higher Education Landscape

components of a conceptual web based application: a component for networking, one for accessing the materials, others to enable data publishing, communication, and components for online training, research, evaluation. These can be seen as independent software components which expose services.

There is also the notion of Microservices architecture (see Figure 7), which presents some different aspects when compared to SOA:

- In both architectures, each service - unlike a monolithic architecture - has a certain responsibility. Thus, services can be developed in various technology stacks which bring technology diversity into the development team. The development of services can be organized within multiple teams, however, each team needs to know about the common communication mechanism in SOA.

- In microservices, services can operate and be deployed independently of other services, unlike SOA. So, it is easier to deploy new versions of services frequently or scale a service independently.

- In SOA, services share the data storage while each service can have an independent data storage in microservices. Sharing data storage has its pros and cons. For example, the data can be re-used between the different services. This will foster stronger dependency and tighter coupling within services.

- Last but not least, the main difference between SOA and microservices lies in the size and the scope. Microservice has to be significantly smaller than what SOA tends to be and mainly is a small(er) independently deployable service. On the other hand, a SOA can be either a monolith or it can be comprised of multiple microservices (Miri, 2016).

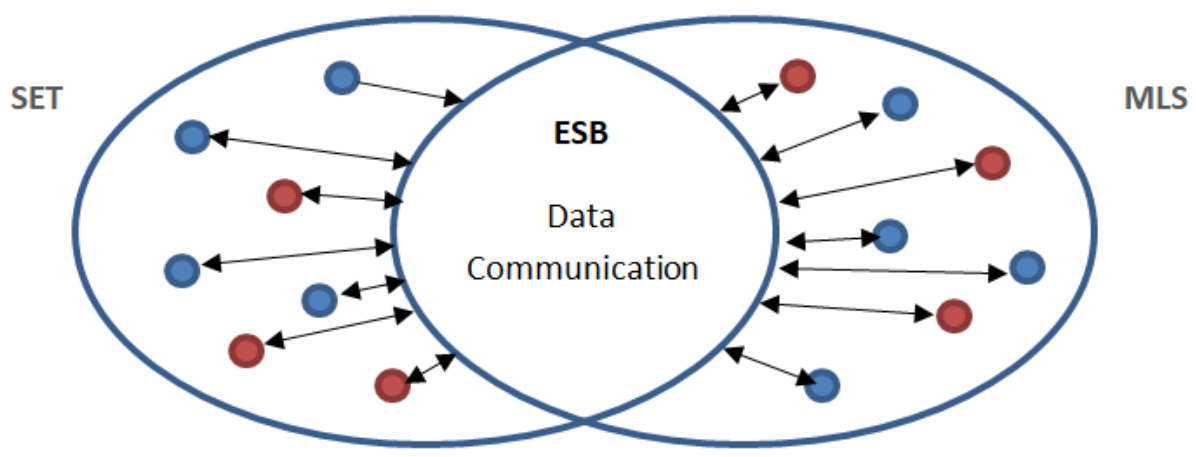

Figure 8. Consumers (blue), providers (red) and ESB inside SET and MLS

DE GRUYTER OPEN
Timisoara Journal of Economics and Business | ISSN: 2286-0991 | www.tjeb.ro Year 2017 | Volume 10 | Issue 1 | Pages: 120-133 
Popa Strainu, R. M., \& Georgescu, M. (2017).

We actually needed an architectural model which produces a robust and modern integration between customers and suppliers at business level and also a technological integration of the database, web services and client application (Dospinescu, Perca 2010).

SOA is suited due to the fact that in education and not only, most parts of the IS already exist, and SOA is suited to adapt and integrate technologies, because using REST full web services, it can provide results in XML or Json formats which are well known and easy to use and to parse in web applications. And starting from the components of each system, we can see them as microservices with dedicated functionalities, so the difference between SOA and microservices may bring a plus in implementations or integration, because depending on each component particularity or characteristics, we can consider using one type of architecture or another, or to combine them. To avoid any confusions, we can say that the integration between or inside our two systems can be done using a service based architecture (SBA) to encompass both paradigms. The communication inside each system can also be mediated by a SBA.

We can state that the consumers from MLS can request resources from the providers from SET or vice versa. At the same time, each system has its own consumers and providers. Starting from the fact that these systems share: learning, people, data, communication components it's somehow obvious that SBA (which uses data and communication elements) is not necessarily the link between those two systems, but mostly the engine of each system which makes possible data transfer, data access, networking, communication, etc. The direct communication between those systems is done via an ESB (see figure 8), but they might not even need to communicate, because the central pieces are the shared components and ESB which provide the support for the other three different components (hardware, software and environment).

\section{Conclusions}

This research identified two major and important systems well known today as educational technologies and mobile learning. We identified the composing elements of these systems, we confirmed that mobile learning is a system and not necessarily a component of the educational technologies system. Starting from here, the two separate entities (systems) need to communicate, being by their nature open systems.

Therefore, from an architectural point of view, the exchange of data between those two can be accomplished by a combination of services (which can be SOA or microservices). Due to the fact that these systems share two major components (data and communication), they

\section{DE GRUYTER} OPEN
Timisoara Journal of Economics and Business | ISSN: 2286-0991 | www.tjeb.ro Year 2017 | Volume 10 | Issue 1 | Pages: 120-133 
Popa Strainu, R. M., \& Georgescu, M. (2017).

SOA - the link between modern educational technologies and mobile learning

in the Higher Education Landscape

may not even communicate directly, but by simply using an ESB. SBA can also provide communication inside each system, being by their nature web based.

Further research steps should identify the existing components and try to integrate them so that they can be used both on mobile and on any platform, without constrains, making access to data in an easier manner. The architectural model should be implemented subsequent to a proper business analysis.

\section{Acknowledgement:}

This work was supported by a grant of the Romanian National Authority for Scientific Research and Innovation, CNCS - UEFISCDI, project number PN-II-RU-TE- 2014-4-0748.

\section{References}

Bertalanffy, L. v. (1969). General System Theory. New York: Library of Congress Catalog Care.

Burgeois, D. (2014). Information Systems for Business and Beyound. Saylor Academy.

Dospinescu, O., \& Perca, M. (2010). Technological integration for increasing the contextual level of information. Analele Stiintifice ale Univesitatii Al. I. Cuza din Iasi, 571-581.

El-Hussein, M. O. (2010). Defining Mobile Learning in the Higher Education Landscape. Educational Technology \& Society, 12-21.

Endrei, M., Ang, J., Arsanjani, A., Chua, S., Comte, P., Krogdahl, P., Luo, M., \& Newling, T. (2004). Patterns: Service-Oriented Architecture and Web Services. IBM (RedBooks). Retrieved September 7, 2011, from http://www.redbooks.ibm.com/redbooks/pdfs/sg246303.pdf.

Miri, I. (2016, July). Microservices vs. SOA. Retrieved October 2016, from https://dzone.com/articles/microservices-vs-soa-2

OECD. (2010). Technology-enabled active learning environments: an appraisal. CELE Exchange 2010/7.

Partnership Resource 21. (2009). 21st Century Learning Environments. N/A: 21, Partnership's Resource.

Rosenberg, D. (2010). Modeling Service-Oriented Architectures. Sparx Systems Pty Ltd and ICONIX.

Selwyn, N. (2013). A digital World - Global perspectives on Technology and Education. London: Taylor\&Francis Group.

Unesco. (2013). Policy Guidelines for Mobile Learning, United Nations Educational, Scientific and Cultural Organization. Unesco.

Walonick, D. S. (1993). General Systems Theory. Retrieved from http://www.statpac.org/walonick/systems-theory.htm on 7/25/2016 